\title{
Ovariectomy during the luteal phase influences secretion of prolactin, growth hormone, and insulin-like growth factor-I in the bitch
}

\author{
W.M. Lee ${ }^{\text {a,1 }}$, H.S. Kooistra ${ }^{\text {a }}$, J.A. Mol ${ }^{\text {a }}$, S.J. Dieleman ${ }^{\text {b }}$, A.C. Schaefers-Okkens ${ }^{\text {a,* }}$ \\ ${ }^{a}$ Department of Clinical Sciences of Companion Animals, Faculty of Veterinary Medicine, Utrecht University, Utrecht, The Netherlands \\ ${ }^{\mathrm{b}}$ Department of Herd Health and Reproduction, Faculty of Veterinary Medicine, Utrecht University, Utrecht, The Netherlands
}

Received 7 July 2005; received in revised form 24 November 2005; accepted 1 January 2006

\begin{abstract}
A decline in circulating progesterone concentration plays an important role in the ethiopathogenesis of pseudopregnancy in the bitch. Because growth hormone $(\mathrm{GH})$ and prolactin (PRL) are essential for normal mammogenesis and the secretion of these hormones is influenced by changes in the circulating progesterone concentration, the purpose of this study was to investigate the effects of mid-luteal phase ovariectomy on the 6-h pulsatile plasma profiles of GH and PRL and the basal plasma concentrations of GH, PRL, and insulin-like growth factor-I (IGF-I) in six beagle bitches.

Ovariectomy was followed by only mild or covert signs of pseudopregnancy. The sharp decrease of the plasma progesterone concentration was accompanied by decreased basal plasma concentrations of GH and IGF-I and a rise in basal plasma PRL concentration. GH and PRL were secreted in a pulsatile fashion both prior to and after ovariectomy. The mean basal plasma GH concentration was significantly higher before ovariectomy than on days 1 and 7 after ovariectomy. The mean area under the curve above the zero level $\left(\mathrm{AUC}_{0}\right)$ for $\mathrm{GH}$ was significantly higher before than at 7 days after ovariectomy. The mean area under the curve above basal level $\left(\mathrm{AUC}_{\mathrm{b}}\right)$ and the frequency of $\mathrm{GH}$ pulses at 7 days after ovariectomy were significantly higher than before and 1 day after ovariectomy. Both the mean basal plasma PRL concentration and the mean $\mathrm{AUC}_{0}$ for PRL increased after ovariectomy.

In conclusion, ovariectomy of bitches in the mid-luteal phase stops progesterone-induced GH release from the mammary gland, as evidenced by the lowering of basal plasma GH levels, the recurrence of GH pulsatility, and the lowering of circulating IGF-I levels. The sudden lowering of plasma progesterone concentration is probably a primary cause of a prolonged increase in PRL secretion. These observations underscore the importance of similar, albeit less abrupt, hormonal changes in the cyclical physiological alterations in the mammary gland and in the development of pseudopregnancy.
\end{abstract}

(C) 2006 Elsevier Inc. All rights reserved.

Keywords: Dog; Pulsatile secretion; Progesterone; Pseudopregnancy; Mammary glands

\footnotetext{
* Corresponding author at: Department of Clinical Sciences of Companion Animals, Faculty of Veterinary Medicine, Utrecht University, P.O. Box 80.154, NL-3508 TD Utrecht, The Netherlands. Tel.: +31 30 2539411; fax: +31302518126.

E-mail address: A.C.Schaefers-Okkens@vet.uu.nl (A.C. Schaefers-Okkens).

${ }^{1}$ Present address: Department of Veterinary Medicine, Veterinary Teaching Hospital, College of Veterinary Medicine, National ChungHsing University, 402 Taichung City, Taiwan, Republic of China.
}

\section{Introduction}

The oestrous cycle of the Canidae differs considerably from that of other species. In the domestic bitch the oestrous cycle is characterized by a follicular phase with spontaneous ovulation, followed by a luteal phase of about 75 days and a non-seasonal anoestrus of 2-10 months [1]. In contrast to most other mammalian 
species, the bitch has a luteal phase that is comparable in duration to pregnancy $[2,3]$.

The decline in plasma progesterone concentration in the second half of the luteal phase may be associated with the development of overt pseudopregnancy. A mild or covert form of pseudopregnancy is present in almost all non-pregnant dogs during this part of the oestrous cycle $[1,4]$. Consistent with the concept that a rapid lowering of plasma progesterone concentration plays a pivotal role, overt pseudopregnancy often occurs after ovariectomy performed during the luteal phase. On the other hand, Gobello et al. [5] found that the abrupt decrease in progesterone concentration does not automatically lead to overt pseudopregnancy. In their study only bitches predisposed to pseudopregnancy exhibited the typical signs of pseudopregnancy. The typical signs of overt pseudopregnancy are characterized by changes in behaviour, such as nest building, mothering of objects, reluctance to leave the home, and aggression. In addition, pseudopregnancy is associated with proliferation and differentiation of mammary gland tissue. The mammary glands may develop to such an extent that the body contour closely resembles that in late pregnancy or lactation. The mammary secretion varies from only a few drops of a clear or brownish fluid to considerable amounts of true milk [6].

It has been suggested that an elevation in plasma prolactin (PRL) concentration is responsible for the development and maintenance of pseudopregnancy symptoms [5-8]. Indeed, the decline in plasma progesterone concentration during the second half of the luteal phase is associated with an increase in the plasma PRL concentration [9-12]. Furthermore, overt pseudopregnancy can be treated effectively by PRL-lowering drugs. Because dopamine has been recognised as the main inhibitory neural signal for PRL release, while several other substances are known to have PRL-releasing activity, such as serotonin and oxytocin [13-15], especially dopamine agonists and serotonin antagonists are used in the treatment for overt pseudopregnancy $[7,8]$.

PRL plays an essential role in normal mammogenesis. Studies in knockout mice lacking the PRL receptor have revealed that lobuloalveolar development in the mammary gland is strictly dependent on the presence of PRL [16]. As alveolar growth and development mainly occur during advanced stages of mammary development, which is during the second part of the luteal phase in the bitch, the lobuloalveolar development coincides with the highest plasma PRL concentrations.

Growth hormone $(\mathrm{GH})$ also plays a role in the development of mammary tissue. During the first stages of mammary gland formation $\mathrm{GH}$, in concert with $\mathrm{GH}$ - induced insulin-like growth factor-I (IGF-I) and some of the IGF-binding proteins, contributes to proliferation of mammary gland epithelium [17]. The secretion of $\mathrm{GH}$ is influenced by progesterone [18]. The high plasma progesterone concentrations during the first half of the luteal phase induce elevated plasma GH concentrations in the bitch [19]. The long exposure to high circulating progesterone levels during each oestrous cycle may even result in GH excess [20]. The progesteroneinduced $\mathrm{GH}$ production in this species occurs in foci of hyperplastic ductular epithelium of the mammary gland [21].

It is now generally accepted that GH and PRL are secreted in a pulsatile fashion and that analysis of this pattern of secretion is more sensitive to identify changes in hormone release than basal hormone concentrations. Data concerning the effects of ovariectomy during the mid-luteal phase on the pulsatile plasma GH and PRL profiles and the basal plasma GH and IGF-1 concentrations are lacking in the bitch. Therefore, the purpose of this study was to investigate the influence of mid-luteal phase ovariectomy, i.e., a sudden decrease in plasma progesterone concentration, on the basal levels and 6-h pulsatile plasma profiles of these hormones in six beagle bitches. In addition, the development of pseudopregnancy in these bitches was investigated.

\section{Materials and methods}

\subsection{Animals}

Six healthy beagle bitches, 7-9 years of age and having no history of overt pseudopregnancy, were used in this study. They were accustomed to the laboratory environment and procedures such as collection of blood samples. They were housed in pairs in indoor-outdoor runs, fed a standard commercial dog food once daily, and given water ad libitum.

All dogs were examined three times per week for the presence of swelling of the vulva and serosanguinous vaginal discharge, which were considered to signify the onset of pro-oestrus. From the onset of pro-oestrus, plasma progesterone concentration was measured three times per week until it exceeded $16 \mathrm{nmol}^{-1}$, which is when ovulation is assumed to occur [22-24].

Each bitch was ovariectomized at 25-40 days after ovulation. After premedication with $0.05 \mathrm{mg}$ atropine $\mathrm{kg}^{-1}$ body mass i.m. and $2 \mathrm{mg}$ carprofen $\mathrm{kg}^{-1}$ body mass i.v. anaesthesia was induced with $5 \mathrm{mg}$ propofol $\mathrm{kg}^{-1}$ body mass i.v. and $15 \mu \mathrm{g}$ fentanyl $\mathrm{kg}^{-1}$ body mass i.v. After endotracheal intubation, anaesthesia was maintained with $50 \% \quad \mathrm{O}_{2}$ and $50 \% \quad \mathrm{~N}_{2} \mathrm{O}$ at $11 / \mathrm{min}$, 
together with $20 \mathrm{mg}$ propofol $\mathrm{kg}^{-1}$ body mass and 10 $20 \mu \mathrm{g}$ fentanyl $\mathrm{kg}^{-1}$ body mass per hour (constant infusion). The surgery was performed as described previously [25].

\subsection{Sample collection}

The study protocol was approved by the Ethics Committee of the Faculty of Veterinary Medicine, Utrecht University, The Netherlands.

Blood samples were collected at 15-min intervals between 08:00 and 14:00 h, 6 days before, 1 day after, and 7 days after ovariectomy. Blood samples taken at 15-min interval are sufficient to recognize pulses of PRL and GH in this stage of the luteal phase [12]. In addition, blood samples for measurement of the plasma concentrations of GH and PRL were collected daily from 4 days before until 7 days after ovariectomy. Blood samples for measurement of the plasma concentrations of progesterone and IGF-I were collected on alternate days from 4 days before until 7 days after ovariectomy. Blood samples were collected by jugular venipuncture in chilled EDTA-coated tubes and the plasma was stored at $-20{ }^{\circ} \mathrm{C}$ until assayed.

\subsection{Hormone measurements}

Plasma GH concentrations were measured by a homologous radioimmunoassay (RIA) as described by Eigenmann and Eigenmann [20]. The intra-assay and interassay coefficients of variation were $3.8 \%$ and $7.2 \%$, respectively. The sensitivity of the assay was $0.3 \mu \mathrm{g} 1^{-1}$.

Plasma IGF-I concentrations were measured by a heterologous RIA as described previously [26]. The intra-assay and interassay coefficients of variation were $4.7 \%$ and $15.6 \%$, respectively, at an IGF-I concentration of $175 \mu \mathrm{g} 1^{-1}$. The sensitivity of the assay was $6 \mu \mathrm{g} \mathrm{l}^{-1}$.

Plasma progesterone concentrations were measured by a previously validated RIA $[27,28]$. The intra-assay and interassay coefficients of variation were $11 \%$ and $14 \%$, respectively. The sensitivity of the assay was $0.13 \mathrm{nmol} \mathrm{l}^{-1}$.

Plasma concentrations of PRL were measured by a previously validated heterologous RIA [28]. The intraassay and interassay coefficients of variation were $3.5 \%$ and $11.5 \%$, respectively. The sensitivity of the assay was $0.8 \mu \mathrm{g}^{-1}$.

\subsection{Data analysis}

The 6-h plasma profiles of PRL and GH were analysed using the Pulsar programme developed by
Merriam and Wachter [28]. The programme identifies pulses by height and duration from a smoothed baseline, using the assay S.D. as a scale factor. The cut-off parameters G1-G5 of the Pulsar programme were set at $3.98,2.4,1.68,1.24$, and 0.93 times the assay S.D., as criteria for accepting pulses $1,2,3,4$, and 5 points wide, respectively, resulting in a false-positive error rate of less than $5 \%$. The smoothing time, a window used to calculate a running mean value, was set at $5 \mathrm{~h}$. The weight assigned to peaks was 0.05 for the plasma profiles of $\mathrm{GH}$ and 0.1 for the plasma profiles of PRL. The $A, B$, and $C$ values of the Pulsar programme, used to calculate the variance of the assay, were set at $A=0$, $B=7.2$, and $C=5$ for the plasma profile of $\mathrm{GH}$, and $A=0.29, B=3.56$, and $C=28.9$ for the plasma profile of PRL. The values extracted from the Pulsar analyses included the overall mean of the smoothed baseline (basal plasma hormone concentration), the number of peaks, the area under the curve above the baseline $\left(\mathrm{AUC}_{\mathrm{b}}\right)$ and the area under the curve above the zero level $\left(\mathrm{AUC}_{0}\right)$.

Differences in the AUCs and the basal plasma hormone concentrations were evaluated by analysis of variance (ANOVA) for repeated measures and differences in pulse frequency were evaluated by the Friedman test. Subsequently, multiple comparisons were performed using the Student-Newman-Keuls test. The average of the mean plasma concentrations before and that after ovariectomy was compared with Student's $t$-test for paired samples. Data are expressed as mean \pm S.E.M. or as median and/or range. $P<0.05$ was considered significant.

\section{Results}

There were mild signs of covert pseudopregnancy after ovariectomy: the mammary glands were slightly swollen and drops of fluid could be milked from them. The average of the mean plasma progesterone concentrations before ovariectomy $\left(41 \pm 9 \mathrm{nmol} \mathrm{l}^{-1}\right)$ was significantly higher $(P=0.009)$ than that after ovariectomy $\left(0.9 \pm 0.3 \mathrm{nmol}^{-1}\right)$. One day after ovariectomy the mean plasma progesterone had already decreased to $2.9 \pm 0.7 \mathrm{nmol}^{-1}$. The average of the mean plasma $\mathrm{GH}$ concentrations before ovariectomy $\left(2.6 \pm 0.3 \mu \mathrm{g}^{-1}\right)$ was significantly higher $(P=0.005)$ than that after ovariectomy $\left(1.2 \pm 0.3 \mu \mathrm{gl}^{-1}\right)$ (Fig. 1). Similarly, the average of the mean plasma IGF-I concentrations before ovariectomy $\left(180 \pm 15 \mu \mathrm{gl}^{-1}\right)$ was significantly higher $(P=0.02)$ than that after ovariectomy $\left(117 \pm 7 \mu \mathrm{g} \mathrm{l}^{-1}\right)$. The average of the mean plasma PRL concentrations before ovariectomy 


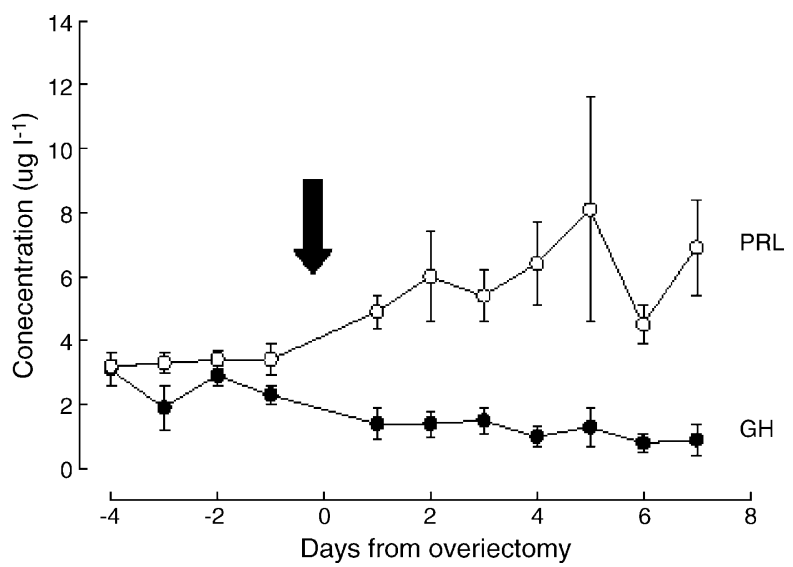

Fig. 1. Mean ( \pm S.E.M.) plasma concentrations of PRL $(\bigcirc)$ and GH (O). Blood samples were collected daily, from 4 days prior to until 7 days after ovariectomy. The day on which ovariectomy (OVX) was performed is indicated by an arrow.

$\left(3.4 \pm 0.4 \mu \mathrm{g}^{-1}\right)$ was significantly lower $(P<0.05)$ than that after ovariectomy $\left(6.0 \pm 1.2 \mu \mathrm{g} l^{-1}\right)$ (Fig. 1).

Analysis of the plasma profiles of GH and PRL by the Pulsar programme revealed that both hormones were secreted in a pulsatile fashion, both prior to and after ovariectomy (Fig. 2). The mean basal plasma GH concentration before ovariectomy was significantly higher $(P=0.004)$ than at 1 and 7 days after ovariectomy. The mean $\mathrm{AUC}_{0}$ for $\mathrm{GH}$ before ovariectomy was significantly higher $(P=0.04)$ than at 7 days after ovariectomy. In contrast, the mean $\mathrm{AUC}_{\mathrm{b}}$ for
$\mathrm{GH}$ at 7 days after ovariectomy was significantly higher $(P=0.003)$ than before and 1 day after ovariectomy. The frequency of GH pulses at 7 days after ovariectomy was also significantly higher $(P=0.01)$ than before and 1 day after ovariectomy (Table 1). The mean basal plasma PRL concentration before ovariectomy was significantly lower $(P=0.03)$ than at 1 and 7 days after ovariectomy. Similarly, the mean $\mathrm{AUC}_{0}$ for PRL before ovariectomy was significantly lower $(P=0.002)$ than at 1 and 7 days after ovariectomy. The differences in the $\mathrm{AUC}_{\mathrm{b}}$ for PRL pulses before and at 1 and 7 days after ovariectomy were not significant (Table 1).

\section{Discussion}

Ovariectomy of the beagle dogs during the midluteal phase resulted in significant changes in the secretion of progesterone, GH, IGF-I, and PRL. The sharp decrease in plasma progesterone concentration was accompanied by a decrease in basal plasma $\mathrm{GH}$ concentration and the $\mathrm{AUC}_{0}$ for $\mathrm{GH}$. These observations are in agreement with previous findings by Kooistra et al. [19], who found basal GH secretion to be higher during stages in which plasma progesterone concentration was high. Also, Selman et al. [18] reported that plasma GH concentration was higher during the luteal phase than during anoestrus. This phenomenon can be explained by the fact that canine mammary gland expresses the gene encoding $\mathrm{GH}$ and that its expression
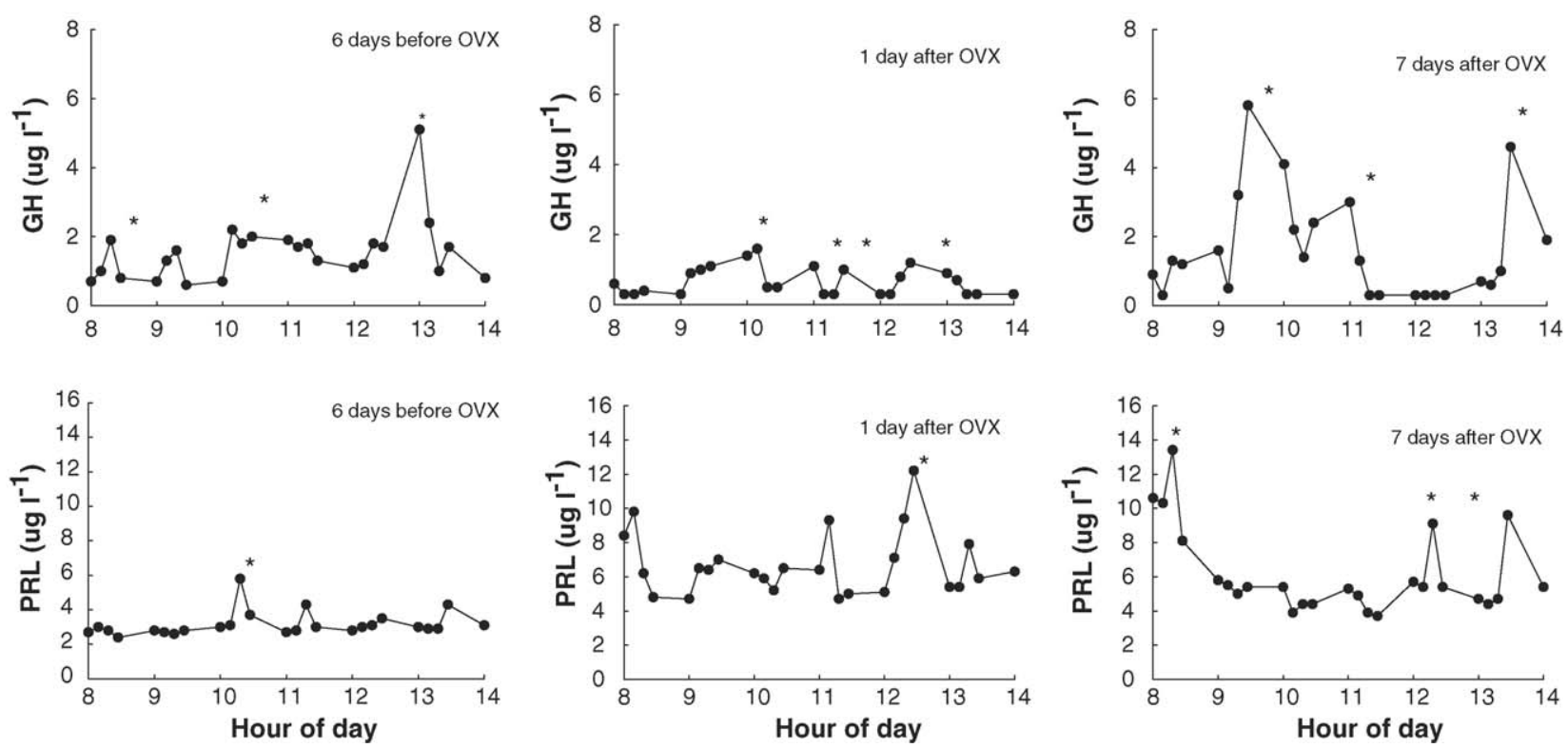

Fig. 2. The 6-h plasma profiles of GH and PRL 6 days before, 1 day after, and 7 days after ovariectomy (OVX) in a 9-year-old beagle bitch. Blood samples were collected at 15-min intervals between 08:00 and 14:00 h. Significant pulses, calculated by the Pulsar programme, are indicated by an asterisk. 
Table 1

Characteristics of the 6-h plasma profiles of GH and PRL in six beagle bitches

\begin{tabular}{|c|c|c|c|}
\hline & 6 days before OVX & 1 day after OVX & 7 days after OVX \\
\hline \multicolumn{4}{|l|}{ GH } \\
\hline Basal GH $\left(\mu \mathrm{g}^{-1}\right)$ & $1.9 \pm 0.4 \mathrm{a}, \mathrm{b}$ & $1.2 \pm 0.4 \mathrm{a}$ & $0.3 \pm 0.1 \mathrm{~b}$ \\
\hline 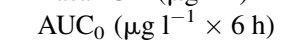 & $12.5 \pm 2.6 \mathrm{a}$ & $8.0 \pm 2.4$ & $5.6 \pm 0.9 \mathrm{a}$ \\
\hline 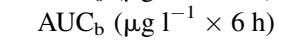 & $1.4 \pm 0.9 \mathrm{a}$ & $1.0 \pm 0.4 \mathrm{~b}$ & $4.6 \pm 0.9 \mathrm{a}, \mathrm{b}$ \\
\hline Freq (pulses/6 h) & $0-3 \mathrm{a}$ & $0-4 \mathrm{~b}$ & $4-6$ a,b \\
\hline \multicolumn{4}{|l|}{ PRL } \\
\hline Basal GH $\left(\mu \mathrm{g}^{-1}\right)$ & $3.2 \pm 0.2 \mathrm{a}, \mathrm{b}$ & $5.0 \pm 0.4 \mathrm{a}$ & $4.4 \pm 0.3 \mathrm{~b}$ \\
\hline $\mathrm{AUC}_{0}\left(\mu \mathrm{g} 1^{-1} \times 6 \mathrm{~h}\right)$ & $20.6 \pm 1.3 \mathrm{a}, \mathrm{b}$ & $33.1 \pm 3.4 \mathrm{a}$ & $33.7 \pm 5.4 \mathrm{~b}$ \\
\hline 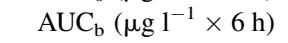 & $1.3 \pm 0.3$ & $3.6 \pm 1.8$ & $7.4 \pm 5.0$ \\
\hline Freq (pulses/6 h) & $0-2$ & $0-4$ & $0-3$ \\
\hline
\end{tabular}

The values are expressed as mean ( \pm S.E.M.) or range. The plasma profiles were measured 6 days before, 1 day after, and 7 days after ovariectomy $(\mathrm{OVX})$. Basal, basal plasma hormone concentration; $\mathrm{AUC}_{0}$, area under the curve above the zero level; $\mathrm{AUC}$, area under the curve above the baseline; Freq, number of pulses per $6 \mathrm{~h}$. A letter indicates a significant difference from the observation with the same letter.

is highly stimulated by progesterone [21,29]. This progesterone-induced mammary $\mathrm{GH}$ production leads to production of IGFs, whereby their growthpromoting effect is modulated by IGF-binding proteins [17]. In the progesterone-dominated phase of the oestrous cycle these hormonal changes promote the physiological proliferation and differentiation of mammary gland tissue. The $\mathrm{GH}$ produced in the canine mammary gland also reaches the systemic circulation, which explains the increased plasma GH level during the luteal phase. The long lasting exposure to high circulating levels of progesterone during each oestrous cycle may even result in GH excess, leading to acromegaly and/or diabetes mellitus [30].

Progesterone-induced, non-episodic GH secretion from the mammary gland may result in partial suppression of the pulsatile release of $\mathrm{GH}$ by the pituitary. Indeed, loss of GH pulsatility has also been reported in the bitch during progestagen-induced GH excess [31]. The cessation of suppression of pituitary $\mathrm{GH}$ secretion by progesterone-induced mammary $\mathrm{GH}$ may explain the significant increase in both the $\mathrm{AUC}_{\mathrm{b}}$ and the pulse frequency for $\mathrm{GH}$ at 7 days after ovariectomy.

Mean plasma IGF-I concentration before ovariectomy was significantly higher than that after ovariectomy. This can be ascribed to the elevated plasma GH levels during the luteal phase. The effects of GH can be divided into rapid metabolic effects and slow hypertrophic effects. The latter effects are mediated by IGF-I. The elevated circulating GH levels during the luteal phase most likely resulted in increased IGF-I secretion from the liver and the kidneys [32]. The elevated plasma IGF-I levels may have contributed to the loss of GH pulsatility before ovariectomy, via a feedback effect on hypothalamic somatostatin secretion [33].

The average of the mean plasma prolactin concentrations determined in these six bitches before surgery $\left(3.4 \pm 0.4 \mu \mathrm{g}^{-1}\right)$ were similar to the concentrations determined in Beagle bitches with the same housing facilities using the same RIA method as used in an earlier study in a comparable stage of the luteal phase $\left(3.0 \pm 0.4 \mu \mathrm{g}^{-1}\right)$ [12].

Stress of surgery and anaesthesia may cause a sharp increase of PRL, which can last for $30 \mathrm{~h}$ [24]. It is however, likely that the increased PRL secretion 1 day after ovariectomy at least partially, and at 7 days after ovariectomy totally was due to the decline in plasma progesterone concentration. Galac et al. [34] demonstrated a sharp increase in plasma PRL concentration in pregnant bitches after the administration of a progesterone receptor blocker. Also, in pregnant and overtly pseudopregnant bitches plasma PRL concentration begins to rise 4 weeks after ovulation, which coincides with the initial decline in plasma progesterone concentration $[4,9,10]$. Even in bitches that are not overtly pseudopregnant and have relatively low plasma PRL concentrations, the gradual decrease in plasma progesterone concentration during the second half of the luteal phase is associated with an increase in PRL release [12].

Ovariectomy in the mid-luteal phase in our bitches, without a history of pseudopregnancy, only resulted in some mammary enlargement and some milk secretion (covert pseudopregnancy). Gobello et al. [5] also reported that bitches having no history of pseudopregnancy do not develop overt pseudopregnancy after ovariectomy during the luteal phase.

Overt pseudopregnancy is a common problem in Afghan hounds [7]. The mean plasma PRL concentration 
in the second half of the luteal phase in the pseudopregnant bitches is significantly higher than that in non-pseudopregnant bitches of this breed during the first part of the luteal phase. The latter PRL values are similar to the mean plasma PRL level during the entire luteal phase in beagle bitches having no history of overt pseudopregnancy [7]. Although the plasma PRL concentration in the beagle bitches in the present study increased significantly after ovariectomy, the mean basal plasma PRL concentration was much lower than that observed in the pseudopregnant Afghan hounds. This suggests that high plasma PRL concentrations are required for the development of overt pseudopregnancy. It may therefore be expected that in bitches regularly developing overt pseudopregnancy the increase in PRL after ovariectomy will be greater and more sustained than in bitches having no history of pseudopregnancy, although levels of circulating prolactin do not necessarily determine the development of pseudopregnancy. An universal circulating prolactin threshold for triggering pseudopregnancy in the bitch is unlikely to exist. In addition, research in women has uncovered a degree of molecular heterogeneity for prolactin with different biopotencies associated with varying molecular forms of the hormone [35]. In dogs, the presence of molecular heterogeneity for PRL was recently reported in metoestrous bitches. Therefore, differences in the bioactivity versus immunoreactivity ratios of canine PRL in some bitches could account, at least partly, for the lack of consistency between immunoassayable circulating levels of canine PRL and the presence of a biological response, namely pseudopregnancy [36]. However, it is likely that by measuring prolactin levels in the same bitch a significant rise will be observed at the start of overt pseudopregnancy [7]. This may be a reason to avoid ovariectomy in the luteal phase in bitches which regularly have shown symptoms of overt pseudopregnancy.

In conclusion, ovariectomy of bitches in the midluteal phase stops progesterone-induced GH release from the mammary gland, evidenced by lowering of the basal plasma GH concentration, the recurrence of GH pulsatility, and lowering of the circulating IGF-I concentration. In addition, ovariectomy also causes plasma PRL concentration to rise, probably due to the sudden decline in plasma progesterone concentration. Because GH, in concert with IGF-I and some of the IGF-binding proteins, contributes to proliferation of mammary gland epithelium and because PRL promotes lobuloalveolar development, the transition from progesterone-induced elevated GH levels to a PRLdominated phase may facilitate the development of pseudopregnancy. However, in bitches with no history of overt pseudopregnancy, only minor signs of pseudopregnancy may be expected.

\section{Acknowledgments}

The authors are grateful for the technical assistance of Mrs. M.E. van Wolferen, Mrs. J. Wolfswinkel, Mr. H.G.H. van Engelen, Mr. F.M. Riemers, and Mrs. D.M. Blankenstein.

\section{References}

[1] Schaefers-Okkens AC. Estrous cycle and breeding management of the healthy bitch. In: Ettinger SJ, Feldman EC, editors. Textbook of veterinary internal medicine. Diseases of the dog and cat. 6th ed., Philadelphia: Saunders; 2005. p. 1640-9.

[2] Edqvist LE, Johansson EDB, Kasstrom H, Olsson SE, Richkind M. Blood plasma levels of progesterone and estradiol in the dog during the estrous cycle and pregnancy. Acta Endocrinol 1975;78:554-64.

[3] Concannon PW, Powers ME, Holder W, Hansel W. Pregnancy and parturition in the bitch. Biol Reprod 1977;19:517-26.

[4] Jöchle W. Prolactin in canine and feline reproduction. Reprod Domest Anim 1997;32:183-93.

[5] Gobello C, Baschar H, Castex G, de la Sota RL, Goya RG. Dioestrous ovariectomy: a model to study the role of progesterone in the onset of canine pseudopregnancy. J Reprod Fertil 2001;57(Suppl.):55-60.

[6] Rijnberk A. Hypothalamus-pituitary system. In: Rijnberk A, editor. Clinical endocrinology of dogs and cats. Dordrecht/ Boston: Kluwer Academic Publishers; 1996. p. 11-34.

[7] Okkens AC, Dieleman SJ, Kooistra HS, Bevers MM. Plasma concentrations of prolactin in overtly pseudopregnant Afghan hounds and the effect of metergoline. J Reprod Fertil 1997;51(Suppl.):295-301.

[8] Gobello C, de la Sota RL, Goya RG. Study of the change of prolactin and progesterone during dopaminergic agonist treatments in pseudopregnant bitches. Anim Reprod Sci 2001;66:257-67.

[9] De Coster R, Beckers JF, Beerens D, De Mey J. A homologous radioimmunoassay for canine prolactin: plasma levels during the reproductive cycle. Acta Endocrinol 1983;103:473-8.

[10] Onclin K, Verstegen JP. Secretion patterns of plasma prolactin and progesterone in pregnant compared with nonpregnant diestrous beagle bitches. J Reprod Fertil 1997;51(Suppl.): 203-8.

[11] Overgaauw PA, Okkens AC, Bevers MM, Kortbeek LM. Incidence of patent toxocara infection in bitches during the oestrous cycle. Vet Quart 1998;20:104-7.

[12] Kooistra HS, Okkens AC. Secretion of growth hormone and prolactin during progression of the luteal phase in healthy dogs: a review. Mol Cell Endocrinol 2002;97:167-72.

[13] Ben-Jonathan N, Laudon M, Garris PA. Novel aspects of posterior pituitary function: regulation of prolactin secretion. Front Neuroendocrinol 1991;12:231-77.

[14] Gartwaite TL, Hagen TC. Evidence that serotonin stimulates a prolactin-releasing factor in the rat. Neuroendocrinology 1979;29:215-20. 
[15] Johnston CA, Negro-Vilar A. A role of oxytocin on prolactin secretion during proestrus and in different physiological or pharmacological paradigms. Endocrinology 1988;122:341-50.

[16] Brisken C, Kaur S, Chavarria TE, Binart N, Sutherland RL, Weinberg RA, et al. Prolactin controls mammary gland development via direct and indirect mechanisms. Dev Biol 2002;210:96-106.

[17] Mol JA, Selman PJ, Sprang EPM, Van Neck JW, OosterlakenDijksterhuis MA. The role of progestins, insulin-like growth factor (IGF) and IGF-binding proteins in the normal and neoplastic mammary gland of the bitch: a review. J Reprod Fertil 1997;51(Suppl.):339-44.

[18] Selman PJ, Mol JA, Rutteman GR, Rijnberk A. Progestins and growth hormone excess in the dog. Acta Endocrinol 1991;125(Suppl. 1):42-7.

[19] Kooistra HS, den Hertog E, Okkens AC, Mol JA, Rijnberk A. Pulsatile secretion pattern of growth hormone during the luteal phase and mid-anoestrus in beagle bitches. J Reprod Fertil 2000;119:217-22.

[20] Eigenmann JE, Eigenmann RY. Radioimmunoassay of canine growth hormone. Acta Endocrinol 1981;98:514-20.

[21] Selman PJ, Mol JA, Rutteman GR, van Garderen E, Rijnberk A. Progestin-induced growth hormone excess in the dog originates in the mammary gland. Endocrinology 1994;134:287-92.

[22] Concannon PW, Hansel W, Mcentee K. Changes in LH, progesterone and sexual behavior associated with preovulatory luteinization in the bitch. Biol Reprod 1977;17:604-13.

[23] Wildt DE, Panko WB, Chakraborty PK, Seager SW. Relationship of serum estrone, estradiol-17beta and progesterone to $\mathrm{LH}$, sexual behavior and time of ovulation in the bitch. Biol Reprod 1979;20:648-58.

[24] Okkens AC, Dieleman SJ, Bevers MM, Willemse AH. Evidence for the non-involvement of the uterus in the lifespan of the corpus luteum in the cyclic dog. Vet Quart 1985;7:169-73.

[25] Okkens AC, Kooistra HS, Nickel RF. Comparison of long-term effects of ovariectomy versus ovariohysterectomy in bitches. J Reprod Fertil 1997;51(Suppl.):227-31.
[26] Nap RC, Mol JA, Hazewinkel HA. Age-related plasma concentrations of growth hormone $(\mathrm{GH})$ and insulin-like growth factor I (IGF-I) in Great Dane pups fed different dietary levels of protein. Domest Anim Endocrinol 1993;10:237-47.

[27] Dieleman SJ, Schoenmakers HJ. Radioimmunoassays to determine the presence of progesterone and estrone in the starfish Asterias rubens. Gen Comp Endocrinol 1979;39:534-42.

[28] Merriam GR, Wachter KW. Algorithms for the study of episodic hormone secretion. Am J Physiol 1982;243:E310-20.

[29] Mol JA, van Garderen E, Rutteman GR, Rijnberk A. New insights in the molecular mechanism of progestin-induced proliferation of mammary epithelium: induction of the local biosynthesis of growth hormone $(\mathrm{GH})$ in the mammary glands of dogs, cats and humans. J Steril Biochem Mol Biol 1996;57:6771.

[30] Eigenmann JE, Eigenmann RY, Rijnberk A, Van Der Gaag I, Zapf J, Froesch ER. Progesterone-controlled growth hormone overproduction and naturally occurring canine diabetes and acromegaly. Acta Endocrinol 1983;104:167-76.

[31] Watson ADJ, Rutteman GR, Rijnberk A, Mol JA. Effect of somatostatin analogue SMS 201-995 and antiprogestin agent RU486 in canine acromegaly. Front Horm Res 1987;17:193-8.

[32] Corpas E, Harman SM, Blackman MR. Human growth hormone and human aging. Endocr Rev 1993;14:20-39.

[33] Berelowitz M, Szabo M, Frohman LA, Firestone S, Chu L, Hintz RL. Somatomedin-C mediates growth hormone negative feedback by effects on both the hypothalamus and the pituitary. Science 1981;212:1279-81.

[34] Galac S, Kooistra HS, Butinar J, Bevers MM, Dieleman SJ, Voorhout G, et al. Termination of mid-gestation pregnancy in bitches with aglepristone, a progesterone receptor antagonist. Theriogenology 2000;53:941-50.

[35] Sinha YN. Structural variants of prolactin: occurence and physiological significance. Endocr Rev 1995;6:354-69.

[36] Gobello C, de la Sota RL, Goya RG. A review of canine pseudocyesis. Reprod Domest Anim 2001;36:283-8. 